\title{
Pollen Grain and Hybridization Studies in the Genus Capsicum
}

\author{
Tomi Lois OLATUNJI, Joseph Akintade MORAKINYO \\ University of Ilorin, Department of Plant Biology, Faculty of Life Sciences, PMB 1515, \\ Ilorin,Nigeria; tomi.olatunji@yahoo.com ("correspondingauthor);morakinyoja@yahoo.com
}

\begin{abstract}
The current study aimed to evaluate the pollen viability of the commonly cultivated varieties of Capsicum species and assessed the potentials for gene exchange among the genotypes through hybridization studies. Capsicum annuum var. abbreviatum, C. annuиm var. acuminatum, C. annumm var. grossum and $C$. frutescens var. baccatum were the species and varieties used in this study. The present findings indicated that the percentage of pollen viability varied in the studied Capsicum genotypes. The highest pollen viability was obtained in $C$. annuum var. abbreviatum (96.3\%), followed by C. annuиm var. grossum (95\%), and $C$. annuum var. acuminatum (91.1\%). The lowest pollen viability was recorded in $C$. frutescens var. baccatum (86.2\%). The pollen viability was high in most varieties indicating that meiosis is normal, resulting in viable pollen grains. Several intraspecific and interspecific crosses were performed among the Capsicum genotypes and three putative hybrid fruits were produced. Percentage successes obtained in the crosses were low and comparable in both intra and inter-specific crosses. In the entire crosses pattern, pollination success of $10 \%$ was recorded for $C$. frutescens var. baccatum and $C$. annuum var. acuminatum. Knowing the nature and viability of pollen grains may help in predicting the success rate of hybridization and the successful crosses between C. frutescens var. baccatum and C. annuum var. acuminatum suggest that these two varieties are the closest genetically.
\end{abstract}

Keywords: emasculation, gene exchange, interspecific crosses, intraspecific crosses, pollen viability

\section{Introduction}

The Solanaceae family comprises many economically important food and industrial crops such as potato, tobacco, tomato, garden egg, petunia and pepper (Capsicum). Solanaceae is an important source of almost 300 alkaloids (AlWadi, 2007). Solanine, scopolamine, atropine and hyoscyamine are the key alkaloids of the family (Kalifa $e t$ al., 1998).

The genus Capsicum consists of approximately 22 wild and 5 domesticated species (Bosland and Votava, 2000). The domesticated species include $C$. annuum, $C$. frutescens, $C$. chinenses, C. baccatum, and C. pubescens (Bosland and Votava, 2000). Most Capsicum fruits are pungent, because the placenta accumulates capsaicinoids (e.g., capsaicin) an alkaloid that is a digestive stimulant, and an important ingredient of daily diet with many other medicinal properties (Zewdie and Bosland, 2001; Thompson et al., 2005). Capsicum species can be divided into several groups based on fruit/pod characteristics such as pungency, colour, shape, flavour, and size (Bosland and Votava, 2000). Despite their vast trait differences most cultivars of peppers commercially cultivated belongs to the species $C$. annuum $\mathrm{L}$. (Smith et al., 1987; Bosland, 1992). The fruit colour is due to the presence of total carotenoid pigments which consists mainly of capsanthin and capsorubin in red fruits and $\beta$ - carotene and violaxanthin in yellow-orange fruits (Bosland and Votava,
2000; Kumar et al., 2003). The pharmaceutical utilization of capsaicinoids is attributed to its antioxidant, anticancer, antiarthritic, and analgesic properties (Bosland and Votava, 2000). In addition, pepper fruits are valuable due to their richness in ascorbic acid (Bosland and Votava, 2000).

Pepper is one of the major revenue sources in Nigeria and in the world, it is most crucial and most used condiment (Showemimo and Olanrewaju, 2000). In order to improve the Capsicum productivity, one way is to create a superior pepper genotype. The development of a basic population to create the novel varieties can be conducted in several ways, e.g. through hybridization or crossbreeding since it attains the direct results, such as genetic variability of progeny, heterosis and fixation of desirable traits (Zecevic et al., 2003). Diallel crossing, as one of the methods enables evaluation of parents and gives information regarding the genetic control of quantitative traits which is important for choosing breeding methods (Zecevic et al., 2003). Interspecific hybridization is important in plant breeding as a tool for gene transfer from one genotype, usually a wild species, to another, cultivated genotype that takes the desired gene (Hajjar and Hodgkin, 2007). However, the cross between species may be inconsistent or incompatible due to the existence of a set of pre- and post-zygotic barriers (Hajjar and Hodgkin, 2007). Pre-zygotic barriers can be: the absence of pollen grain germination and the delay or inhibition of pollen tube growth (Hajjar and Hodgkin, 2007). After fertilization, the main barriers are embryonic death due to endosperm 
Table 1. Description of pepper plants used in this study

\begin{tabular}{|c|c|c|}
\hline Variety & Voucher Number & Description \\
\hline C. annuum var. abbreviatum Fingerh & UIH 001/532 & $\begin{array}{l}\text { Medium sized annual plant, small, round and wrinkled fruit with hot taste, one } \\
\text { pedicel per node }\end{array}$ \\
\hline C. annuum var. acuminatum Fingerh & UIH 002/532 & $\begin{array}{l}\text { Medium sized annual plant, long pointed and pendant fruit with hot taste, one } \\
\text { pedicel per node }\end{array}$ \\
\hline C. frutescens var. baccatum (L.) & UIH 004/751 & $\begin{array}{l}\text { Large perennial shrubs; small pointed fruits with very hot taste; } 2-4 \text { pedicel per } \\
\text { node. }\end{array}$ \\
\hline C. annuum var. grossum (L.)Sendt & UIH 003/532 & $\begin{array}{l}\text { Small annual plant, very large bell-shaped fruit with mild taste; one pedicel per } \\
\text { node. }\end{array}$ \\
\hline
\end{tabular}

Table 2. Pollen viability in the studied Capsicum genotype

\begin{tabular}{lccccc}
\hline Varieties & Total no. of pollen & No. of viable pollen & No. of non-viable pollen & \% viable pollen & \% non-viable pollen \\
\hline C.annuum var. abbreviatum & 353 & 314 & 13 & 96.3 & 3.7 \\
C.annuum var. acuminatum & 449 & 409 & 40 & 91.1 & 8.9 \\
C.annuum var. grossum & 518 & 491 & 27 & 95 & 5 \\
C.frutescens var. baccatum & 551 & 475 & 76 & 86.2 & 13.8 \\
\hline
\end{tabular}

degeneration and the total or partial sterility of hybrid plants. These barriers prevented the use of the wild species carrying important genes that are absent in the cultivated forms in breeding programs (Hajjar and Hodgkin, 2007).

In Capsicum, usually no interspecific hybrids involving species belonging to different gene complexes have been obtained due to some incongruity aspects: incompatibility between species, unilateral incompatibility and abortion of the embryo after fertilization and male sterility. Moreover, the more distant two species are genetically, more sterile or unviable their hybrid will be (Onus and Pickersgill, 2004).

One possible post-zygotic barrier can be hybrid male sterility, which can be measured by the viability of pollen grains in the hybrid combination. The pollen viability is an important indicator of the ability of pollen grains to germinate on the flower stigma and fertilize the egg cell, which is a decisive stage in fertilization (Dafni, 1992). Information on pollen viability is essential for studies on the reproductive biology of plant species, allowing the confirmation and understanding of results reported of certain crosses. Pollen viability can be estimated by a number of methods: Lugol solution, Fluorochromatic Reaction (FCR), vital dyes such as tetrazolium salt, germination test in vivo and in vitro and Alexander's solution. According to Alexander (Alexander, 1969), the staining solution is a differential dye that distinguishes viable and unviable pollen grains in most angiosperms, and is considered a quick, cheap and easy technique (Dafni, 1992).

The present study evaluates pollen viability of the commonly cultivated varieties of Capsicum species and assesses the potentials for extent of gene exchange among the varieties.

\section{Materials and Methods}

The study was carried out at University of Ilorin (UNILORIN) Botanical Garden between November 2013 and May 2014. The four pepper varieties (Table 1) used were obtained from Ilorin, Kwara State, Nigeria (latitude $8^{\circ} 30^{\prime} \mathrm{N}$ and longitude $4^{\circ} 33^{\prime} \mathrm{E}$ ).

\section{Pollen grain study}

Evaluation of pollen viability followed the method reported by Alexander (1969). Pollen viability was determined by acetocarmine stainability. Flower buds were collected daily at anthesis

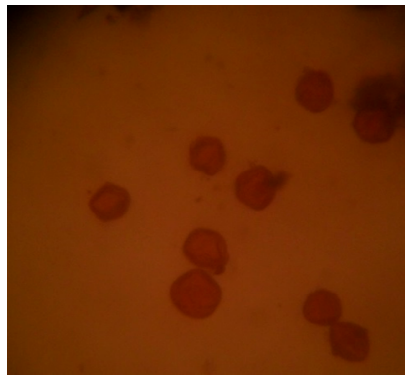

A

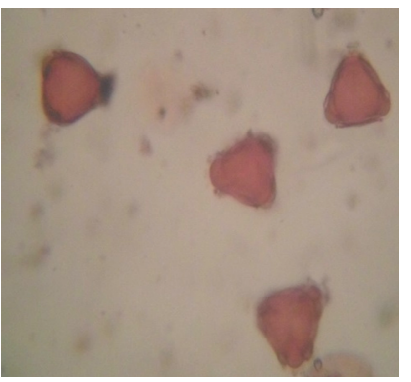

C

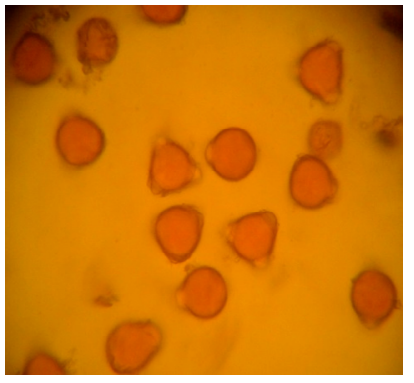

B

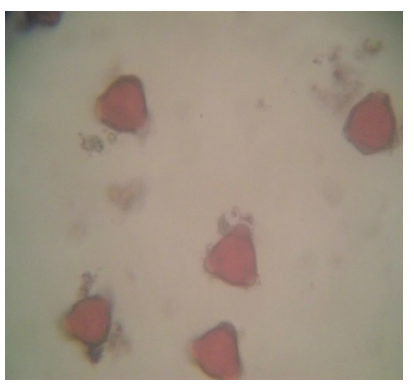

D
Fig. 1. Variation in pollen viability, size and shape in the studied pepper varieties. A-C. annuum var. abbreviatum; B-C. annuum var. acuminatum; C-C. annuum var. grossum; D-C. frutescens var. baccatum. MGX 40

at about 10.00 a.m. The anthers obtained from the flower buds were squashed in drops of aceto-carmine stain on a clean glass slide and covered with clean cover slid. The slides prepared were examined at $\times 40$ magnification of Olympus light microscope. The fully/deeply stained pollen grains with spherical shape were considered viable, while the unstained pollens were taken as nonviable/ sterile. The number of viable and non-viable pollen grain was counted and percentage pollen viability was determined.

\section{Interspecific and intraspecific hybridization}

In order to study the compatibility of the four pepper genotypes, inter and intraspecific crosses were made. At maturity, the four varieties were subjected to a full diallel and reciprocal cross. Controlled pollination was carried out in emasculated flower buds prior to anther dehiscence. This was performed by opening and emasculating flower buds one day before anthesis. 
136

Table 3. Results of intraspecific and interspecific hybridization of the studied Capsicum varieties

\begin{tabular}{|c|c|c|}
\hline Cross combination & Number of flowers & Pollination success (\%) \\
\hline \multicolumn{3}{|c|}{ Interspecific diallel crosses } \\
\hline C. annuum var. abbreviatum $\times$ C. frutescens var. baccatum & 25 & 0 \\
\hline C. annuum var. acuminatum $\times$ C. frutescens var. baccatum & 15 & 0 \\
\hline C. annuum var. grossum $\times$ C. frutescens var. baccatum & 20 & 0 \\
\hline \multicolumn{3}{|c|}{ Interspecific reciprocal crosses } \\
\hline C. frutescens var. baccatum $\times$ C. annuum var. abbreviatum & 25 & 0 \\
\hline C. frutescens var. baccatum $\times$ C. annuum var. acuminatum & 30 & 10 \\
\hline C. frutescens var. baccatum $\times$ C. annuum var. grossum & 15 & 0 \\
\hline \multicolumn{3}{|c|}{ Intraspecific diallel crosses } \\
\hline C. annuum var. abbreviatum $\times$ C. annuum var. acuminatum & 25 & 0 \\
\hline C. annuum var. abbreviatum $\times$ C. annuum var. grossum & 15 & 0 \\
\hline C. annuum var.acuminatum $\times$ C. annuum var. grossum & 20 & 0 \\
\hline \multicolumn{3}{|c|}{ Intraspecific reciprocal crosses } \\
\hline C. annuum var. acuminatum $\times$ C. annuum var. abbreviatum & 25 & 0 \\
\hline C. annuum var. grossum $\times$ C. annuum var. abbreviatum & 15 & 0 \\
\hline C. annuum var. grossum $\times$ C. annuum var. acuminatum & 15 & 0 \\
\hline
\end{tabular}

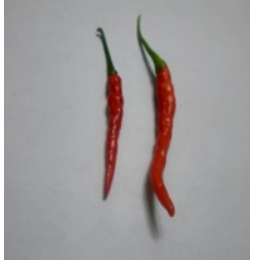

C. frutescens var. C. frutescens

baccatum

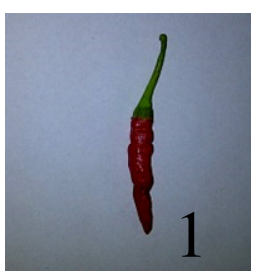

var. baccatum $\mathrm{x}$ C. annuum var. acuminatum

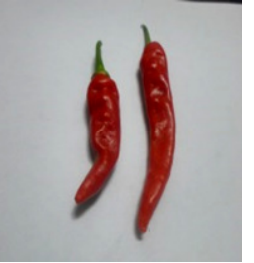

C. annuum var.

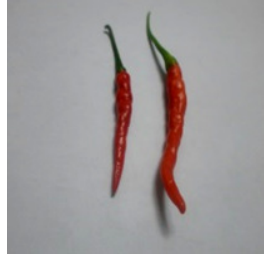

C. frutescens

var. baccatum

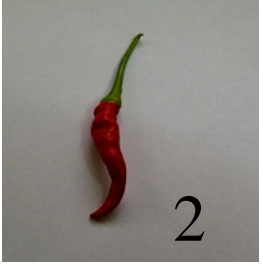

C. frutescens
C.annuum

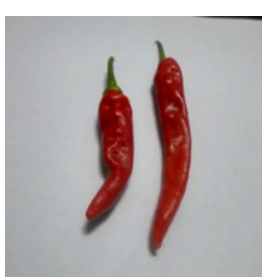

\section{acuminatum}

(1)

\section{$\mathrm{x}$ C. annuum}

\section{var. acuminatum}

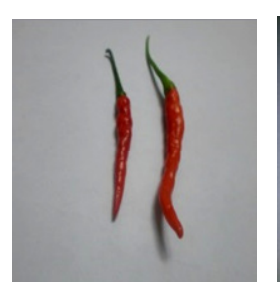

C. frutescens

var. baccatum

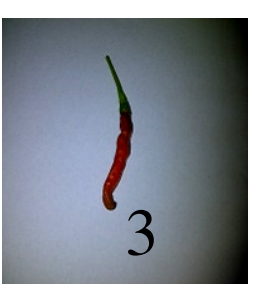

C. frutescens

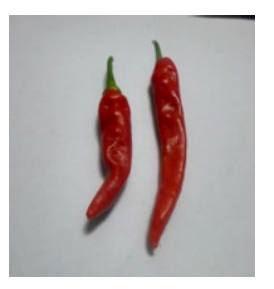

C. annuum

\section{$\mathrm{x} C$. annuum}

\section{var. acuminatum}

Fig. 2. The fruits of parental genotypes and the hybrids. Parents: C. frutescens var. baccatum and C. annuum var. acuminatum

These flower buds were recognized by their characteristic size and tension along the seams of petals. Pollen grains from desirable sources of newly opened flowers were rubbed/dusted directly on the stigma of the emasculated flowers. Thereafter, the pollinated flowers were protected in paper bags to prevent undesirable pollen contamination and the crosses tagged. The data obtained from pollen grain study and hybridization studies were converted into percentage (\%).

\section{Results}

Pollen viability study

The distinction of viable (fertile) from non-viable (infertile) pollen grains was performed with high accuracy.
The results indicated that the percentage of viable pollen varied in the studied Capsicum genotypes. The highest pollen viability was obtained in $C$. annuum var. abbreviatum (96.3\%), followed by C. annuum var. grossum (95\%), and C. annuum var. acuminatum (91.1\%). The lowest rate of pollen viability was recorded in $C$. frutescens var. baccatum (86.2\%) (Table 2).

In addition, the pollen viability of the four studied pepper genotypes was high, indicating that these varieties have a normal meiosis and are therefore were well-adapted to the local environment. Pollen shape in the four varieties varied in size and shape. The shape varied from uniporate to triporate (Fig. 1). 


\section{Hybridization study}

The results of intraspecific and interspecific crosses are summarized in Table 3 . The success of artificial hybridization in almost all the patterns were low both in intra and in interspecific crosses. In all the crosses, pollination success of $10 \%$ was recorded for $C$. frutescens var. baccatum $\times C$. annuum var. acuminatum, as three hybrid fruits were obtained from the 25 flowers pollinated, while zero success was recorded in all others including crosses among the varieties of $C$. annuum (Fig. 2). This is most likely due to low number of pollinators.

\section{Discussion}

The pollen viabilities of the four varieties of pepper were high, indicating that these genotypes had normal meiosis and were therefore fertile, but successful crossing among them depends on their relatedness genetically. For example, intervarietal cross was only successful between varieties of $C$. frutescens var. baccatum and C. annuum var. acuminatum, both having similar pollen shape indicating phylogenetic similarity, whereas, crossing was not successful between plants of dissimilar pollen shapes. This underscores the need for genetic similarities in successful crossing. Carlos et al. (2001) reported high pollen viability in some cultivars of Capsicum annuum. This finding indicates that the non-formation of fruit or the formation of seedless fruits observed in some interspecific crosses established and described in literature cannot be attributed to pollen viability alone (Carlos et al., 2001). Factors influencing hybrid formation rates include genetic similarities, pollen viability, the presence of suitable pollination vectors, efficiency of seed set and seed viability (De Vries et al., 1992).

Recently, considerable attention is given to a number of these factors, but the influence of pollen viability has received relatively little attention (De Vries et al., 1992). However, given the importance of pollen development and function in sexual plant reproduction, it is obvious that pollen viability is a prerequisite for hybrid production (Groot et al., 2003). Therefore, knowledge of the nature and viability of pollen grains may help in predicting hybrid formation (Groot et al., 2003).

Another important consideration in hybridization is the incompatibility status of the parents which may favour specific cross combinations as found in accessions of Cola nitida by Morakinyo (1981).

The studied Capsicum species showed variation in fruit set. The percentage fruit set was higher when $C$. frutescens var. baccatum was hybridized with $C$. annuum var. acuminatum than the other Capsicum species. The low hybridization success recorded in the study indicates the difficulties of crossing within and between species. These results are in agreement with the report presented by Campos et al. (2005), where hybrid combinations of $C$. chinense and $C$. annuum produced either no fruits or fruits with no viable seeds, as observed by Pickersgill (1993) as well. Falusi and Morakinyo (1994) also reported low percentage success (0\%-11.4\%) in both inter and intra specific cross in the genus Capsicum. The percentage fruit set observed in this study were lower than reported by Ribeiro and Melo (2005) for the cross between genotypes of $C$. chinense with $C$. annuum with fruit set rate of
$73.5 \%$ to $100 \%$, using C. chinense as female parent and $87.5 \%$ to $91.5 \%$ in reciprocal crosses. The data, however, do not provide enough evidence to conceive that the collections are not biologically related or that they are reproductively isolated.

On the other hand, the $10 \%$ successful crosses between $C$. frutescens var. baccatum $\times C$. annuum var. acuminatum showed that hybridization is possible in nature and is most probably responsible for the existence of many varieties of pepper that are in cultivation. This corroborates the work of Falusi and Morakinyo (1994). There were little differences in the percentage pollen viability among the pepper genotypes studied but there were great differences in fruit set in reciprocal crosses indicating incipient dioecy as described by Morakinyo (2011).

\section{Conclusion}

The studies revealed that inter and intraspecific cross in Capsicum is possible and can lead to obtain viable seeds and fruits. The successful crosses between $C$. frutescens var. baccatum $\times C$. annuum var. acuminatum suggest that these two varieties are the closest genetically.

\section{References}

Alexander MP (1969). Differential staining of aborted and nonaborted pollen. Stain Technology 44:117-122.

Al-Wadi MH (2007). Palynological and cytological characters of three species of genus Solanum from Saudi Arabia. Journal of Biological Sciences 7(4):626-631.

Bosland PW, Votava EJ (2000). Peppers: Vegetable and Spice Capsicums. CABI Publishing, Wallingford.

Bosland PW (1992). Chiles: a diverse crop. Hort Technology 2:6-10.

Campos KP, Pereira TN, Costa FR, Sudré CP, Monteiro CES,Rodrigues R (2006). Interspecific hybridization among cultivated germplasm in Capsicum. In: The $17^{\text {th }}$ International Pepper Conference. Naples, Florida p 20-20.

Carlos ES, Telma NS, Karina PC (2010). Reproductive characterization of interspecific hybrids among Capsicum species. Crop Breeding and Applied Biotechnology 11:241-249.

Dafni A (1992) Pollination ecology - a practical approach. Oxford University Press, New York.

De Vries FT, Vander Meijden R, Brandenburg WA (1992) Botanical files: A study of the real chances for spontaneous gene flow from cultivated plants to the wild flora of the Netherlands. Gorteria Supplement 1:1-100.

Falusi OA, Morakinyo JA (1994). Intra and inter-specific hybridization in the genus Capsicum. African Crop Science Journal 2:169-171.

Groot MHM, Van de Wiel CCM, Van Tienderen PH, Den Nijs HCM (2003). Hybridization and introgression between crops and wild relatives. University of Amsterdam and Plant Research International, Amsterdam and Wageningen, COGEM Research.

Hajjar R, Hodgkin T (2007). The use of wild relatives in crop improvement: a survey of developments over the last 20 years. Euphytica 156:1-13. 
138

Kalifa SF, Badar AZ, Atta EL, Enani MM (1998). Electrophoresis of seed proteins and their impact on taxonomic relationships in the Solanaceae. Journal of Union of Arab Biologists 5(B):171-180.

Kumar S, Rai SK, Singh M, Kallo G (2003).Genetics of fertility restoration and identification of restorers and maintainers in pepper (Capsicum annuum L.). Capsicum and Eggplant Newsletter 22:79-82.

Morakinyo JA (2011). The state of Cola nitida improvement for kolanut (seed) yield in Nigeria. Nigeria Journal of Genetics 25:110 .

Morakinyo JA, Egbe NE, Olaniran YA (1981). Compatibility studies and yield component of recent Cola nitida selections. Café Cacao Thé (Paris) 15:121-126.

Onus AN, Pickersgill B (2004). Unilateral incompatibility in Capsicum (Solanaceae): occurrence and taxonomic distribution. Annals of Botany 94:289-295.

Pickersgill B, Lu J (1993). Isozyme variation and species relationships in peanut and its wild relatives (Arachis L.-Leguminosae). Theoretical and Applied Genetics 85:550-560.

Ribeiro CSC, Melo RAC (2005). Interspecific hybridization among cultivated germplasm in Capsicum. In: The $17^{\text {th }}$ International Pepper Conference. Naples, Florida p 20-20.
Showemimo FA, Olanrewaju JO (2000). Yield performance heritability and interrelations in some quantitative traits of 'Tatase' pepper (Capsicum annum L.). Journal of Horticultural Science 6(1):25.

Smith PG, Villalon B, Vlla PL (1987). Horticultural classification of pepper grown in the United States. Journal of Horticultural Science 22:11-13.

Thompson RQ, Phinney KW, Welch MJ, White E (2005). Quantitative determination of capsaicinoids by liquid chromatography-electrospray mass spectrometry. Analytical and Bioanalytical Chemistry 381:1441-1451.

Zecevic B, Dordevic R, Pavlovic N, Mijatovic M, Markovic Ž (2003): The effect of parent's germplasm on yield components of F1, F2 and F3 generations of pepper hybrids (Capsicum annuum L.). Acta Horticulturae 729:95-99.

Zewdie Y, Bosland PW (2001). Capsaicinoid profiles are not good chemotaxonomic indicators for Capsicum species. Biochemical Systematics and Ecology 29:161-169. 